\title{
AS DIMENSÕES DO AGIR DOCENTE NO TRABALHO COM A LEITURA
}

\section{AS ACTING TEACHER DIMENSIONS IN WORK WITH READING}

Stephanie Andrade Souza

Maria de Fátima Alves

RESUMO: O objetivo deste trabalho é refletir sobre as dimensões do agir docente que orientam o trabalho do professor para o ensino de leitura. Inserido no âmbito da Linguística Aplicada (LA), utilizaremos como suporte teórico os estudos advindos do Interacionismo Sociodiscursivo (ISD), representado por Bronckart (1999, 2006, 2008), Machado (2004, 2007, 2009), Cristovão (2008), entre outros, e dos estudos provenientes da Clínica da Atividade, cujos representantes são Clot (1999) e Faïta (2002). Em relação aos fundamentos metodológicos, esta pesquisa se caracteriza como qualitativa interpretativista de cunho etnográfico. Para a concretização do objetivo proposto, realizamos entrevistas semi-estruturadas e filmagem de aulas para as sessões de autoconfrontação. Os sujeitos envolvidos na pesquisa são três professores de língua materna do ensino médio da cidade de Campina Grande. Os resultados da análise revelaram que o agir que orienta o trabalho do professor para o ensino de leitura é o agir motivacional da ordem da internalização, revelando assim que os colaboradores da pesquisa trabalham a leitura a partir de motivos mentais particulares.

PALAVRAS-CHAVE: Dimensões do agir docente. Leitura. Ensino.

ABSTRACT: The aim of this paper is to discuss the dimensions of the act teaching that guide the work of teachers for teaching reading. Housed within the Applied Linguistics (LA), we will use as theoretical support the arising studies Interacionism Sociodiscursivo (ISD), represented by Bronckart (1999, 2006, 2008), Machado (2004, 2007, 2009), Christopher (2008), among others, and studies from the activity of the clinic, whose representatives are Clot (1999) and Faita (2002). Regarding the methodological foundations, this research is characterized as qualitative interpretative ethnographic. To achieve the proposed objective, we conducted semi-structured interviews and filming classes for self-confrontation sessions. The subjects involved in this research are three teachers of native high school language of 
Campina Grande. The results of the analysis revealed that the act that guides the work of teachers for teaching reading is the motivational act of internalization order, thus revealing that search employees work reading from private mental reasons.

KEYWORDS: teaching act dimensions. Reading. Teaching. 


\section{AS DIMENSÕES DO AGIR DOCENTE NO TRABALHO COM A LEITURA}

\section{INTRODUÇÃO}

Para tentar compreender o agir docente pesquisas como as desenvolvidas por Cristovão (2008), Machado (2004), entre outras passam a considerar o professor como produtor e receptor de conhecimento e o seu trabalho começa a ser visto em sua totalidade, assim, as "dimensões do agir" (cf. BRONCKART E MACHADO, 2009) são importantes para compreender os posicionamentos que os professores assumem no processo de ensinoaprendizagem, e principalmente o agir direcionado para o trabalho com as competências da leitura, da escrita e da oralidade.

Diante do exposto, autores, a exemplo de Kleiman (2001, 2006), Antunes (2003), Koch \& Elias (2012), Bataus \& Girotto (2013), evidenciam que o ensino de leitura, para alguns professores, torna-se uma atividade desafiadora, e esse desafio ocorre, muitas vezes, devido o docente não ter conhecimento sobre como trabalhar a leitura em sala de aula, o que acaba proporcionando aos discentes um ensino lacunar que, dentre outros problemas, considera o texto como pretexto para o ensino de gramática ou a atividade de leitura como um mero processo de decodificação de palavras, de modo que sabe ler o aluno que pronunciar corretamente as palavras. E esses problemas manifestam-se, por vezes, devido à visão limitada que o professor possui em relação a função da leitura e às práticas de ensino destas no espaço da sala de aula.

Dessa forma, acreditamos ser importante discutir questões relacionadas às dimensões do agir docente e como essas dimensões influenciam o trabalho do professor no ambiente de sala de aula. Assim, o objetivo desse trabalho é identificar que dimensões do agir orientam o trabalho do professor para o ensino de leitura no ensino médio.

Esta pesquisa insere-se no âmbito da Linguística Aplicada (LA), visto que é uma área multidisciplinar e abrangente que apresenta preocupações com questões relacionadas à formação docente e ao uso da linguagem em situações reais. Utilizaremos como sustentação teórica os estudos advindos do Interacionismo Sociodiscursivo (ISD), representado por 
Bronckart (1999, 2006, 2008), Machado (2004, 2007, 2009), Cristovão (2008), entre outros, e da Clínica da Atividade, cujos representantes são Clot (1999) e Faïta (2002) para a discussão sobre o trabalho com a leitura utilizaremos os estudos de Hila (2009), Kleiman (2001, 2006), Antunes (2006), entre outros.

Com relação à metodologia adotada, este trabalho se caracteriza como interpretativista, vinculado à pesquisa qualitativa e de cunho etnográfico. A escolha dessa metodologia, respectivamente, justifica-se devido: a) buscarmos descrever e interpretar os dados obtidos, de modo a compartilhar as constatações com a sociedade; e b) priorizamos a qualidade dos dados obtidos e "preocupa-se com a interpretação do fenômeno, considerando o significado que os outros dão às suas práticas, o que impõe ao pesquisador uma abordagem hermenêutica" (GONSALVES, 2007, p.69c) buscamos fazer parte do contexto pesquisado, de maneira a interagir com os seus sujeitos, não agindo como meros observadores, neutros e distantes do objeto.

No que tange ao local e aos sujeitos da pesquisa, o presente trabalho foi realizado em três escolas públicas estaduais de Ensino Médio da cidade de Campina Grande (PB), e contou com a participação de três sujeitos colaboradores, professores do ensino médio em atuação (por questões éticas, os sujeitos serão identificados como P1, P2 e P3). A escolha desses professores atendeu aos seguintes critérios: trabalhar com leitura; aceitar participar da entrevista e permitir que suas aulas fossem filmadas.

Utilizamos como instrumento para coleta de dados uma entrevista semi- estruturada e narrativas de sessões de autoconfrontação (fizemos três sessões com cada professor) . A escolha desse instrumento de coleta se deu pelo fato de que, na entrevista semi-estruturada, o pesquisador pode abrir espaço para o pesquisado retirar dúvidas e para o pesquisador esclarecer qualquer dúvida que, por ventura, venha surgir através das respostas fornecidas, havendo uma maior interação entre pesquisador e pesquisado.

O artigo encontra-se organizado da seguinte forma: 1) discussão da noção de agir, as concepções de trabalho docente, as vozes discursivas que estão presentes nos discursos dos trabalhadores e as dimensões do agir que norteiam o trabalho docente; 2) análise dos dados obtidos através da entrevista semi-estruturada e das sessões de autoconforntação e, finalmente, as considerações finais.

\section{AGIR DOCENTE À LUZ DO INTERACIONISMO SOCIODISCURSIVO E AS NOÇÕES DE TRABALHO}

O interacionismo sociodiscursivo é constituído por três vertentes epistemológicas: Vertente sociológica, representada por Habermas; Vertente psicológica, defendida por Vygotsky; e Vertente linguística, cuja base centra-se nos estudos de Saussure, no que se refere aos signos linguageiros, e nos estudos de Bakhtin/Volochínov, com estudos dos gêneros discursivos e o processo de interação.

Explicitaremos apenas a corrente sociológica para entendermos a concepção do agir, concepção esta bastante relevante para o presente trabalho. A vertente sociológica envolve os três mundos (objetivo, social e subjetivo), os quais, para Habermas (1981), estão vinculados ao agir. De acordo com Pereira (2009), Habermas redefine as configurações dos mundos, respectivamente, nos seguintes termos: Agir teleológico, que abarca as orientações do mundo objetivo, referente aos parâmetros do ambiente; Agir regulado por normas, regulado por valores e convenções compartilhados pelos membros de um grupo; e Agir dramatúrgico que representa a interiorização do mundo social.

Para Bronckart (2008), o agir é entendido como as variadas intervenções humanas no mundo, e que, por sua vez, incluem diversos tipos de trabalhos, que são decompostos 
e transformados em tarefas, os quais são realizados através de gestos ou atos exclusivos de cada profissão.

A interpretação do agir pode ser construída por análise do uso da linguagem em textos, sejam orais ou escritos, os quais revelam concepções do sujeito ou de determinado grupo que estão associadas as escolhas linguísticas. Portanto, essas escolhas podem se caracterizar tanto pelo o agir comunicativo, estabelecido por ações linguageiras em práticas sociais, quanto pelo agir praxiológico, composto pelo agir prático que auxilia a construção dos três mundos. É com base nessa análise que refletiremos sobre o agir docente.

Nas palavras de Medrado (2011), o agir é norteado por convenções sociais, isto é, valores e regras que permeiam a sociedade, e, portanto ele é examinado, avaliado e interpretado por essas convenções. Ainda segundo a autora, o caráter interpretativo do agir pode indicar aspectos relacionados a três dimensões: motivacional, intencional e recursos do agir, que compreendem respectivamente: distinção das razões que leva ao agir, que podem ser da ordem dos determinantes externos originados no coletivo ou dos motivos interiorizados por uma pessoa particularmente; distinção das finalidades assumidas pelo coletivo e validadas socialmente, e; distinção dos instrumentos externos presentes no ambiente social, que podem ser materiais ou tipificações do agir disponíveis ou não para o indivíduo, e as capacidades internas do agente, podendo ser mentais ou comportamentais. É com base nesta premissa, que entendemos que uma das propostas teóricas do ISD é compreender o agir humano, principalmente o agir implicado no trabalho do professor de língua materna, isto é, o agir docente.

Diante das considerações sobre o agir docente, a discussão ainda se amplia, posto que estudos como o de Mazzillo (2007), retomado por Baricelli (2007), Barbosa (2009) e Rodrigues (2011), categorizam o agir do professor baseando-se nos verbos e nominalizações que predicam os indivíduos, tanto na dimensão individual quanto na coletiva, algumas dessas categorias são descritas da seguinte maneira: a) Agir com instrumentos: implica um agir individual do professor por meios de instrumentos simbólicos ou materiais; b) Agir prescritivo: envolve as relações predicativas indiretas deônticas expressadas por verbos como "dever", "precisar", entre outras e predicativas epistêmicas marcados por verbos como "poder", "ser verdade", etc.; c) Agir afetivo: implicam um agir emocional; d) Agir físico: Verbos que indicam movimentos corporais e gestos.

Um aspecto importante para compreendermos o agir docente se dá a partir das vozes enunciativas, que são entidades que assumem a responsabilidade do que é enunciado, estas podem ser neutras, quando a instância geral de enunciação assume diretamente a responsabilidade do dizer, mas há os casos em que a própria instância de enunciação pode colocar em cena uma ou várias vozes, chamadas de vozes infra-ordenadas e são agrupadas em três categorias: Vozes de personagens- são vozes procendentes dos seres humanos, de outros interlocutores implicados como agente, no discurso; Vozes sociais- advindas de personagens, grupos externos que intervém como instância externa de avaliação do conteúdo; Vozes do autor ou do sujeito empírico- vozes que advêm do próprio indivíduo e que interfere no seu discurso para comentar ou avaliar aspectos do que é enunciado, essas vozes são marcadas pelo pronome pessoal "eu" (BRONCKART, 1999, 2012). Essas vozes, que estão presentes em nossos discursos, podem emitir avaliações, opinião, reflexões, seja de modo implícito ou explicito.

No que tange à noção do trabalho docente, o termo trabalho advém das Ciências do Trabalho e é através dos estudos das correntes teóricas da Clínica da Atividade (doravante CA) e da Ergonomia, representadas por estudiosos como Clot (1999, 2010), Faïta (2002), Nourodine (2002), Lousada (2004), Souza-e-Silva (2002) entre outros, que o trabalho com foco nos estudos linguísticos passa a ser reconhecido. 
Baseando-se nos estudos da Ergonomia o trabalho pode ocorrer sob três dimensões, a priori: 1) trabalho prescrito que se refere à forma como o trabalho está programado para ser realizado; 2) trabalho realizado, isto é, as ações que são utilizadas para realizar o trabalho e; 3) trabalho real, ou realizado (Cf. Bronckart, 1999, 2012), o que foi posto em prática e ainda acrescentaríamos o trabalho interpretado, estabelecido pelo ISD, que considera a atividade através da análise de textos do trabalho executado, ou seja, do trabalho real produzido pelos pesquisadores, portanto, o pesquisador deve atentar para saber discernir entre as vozes de quando é o pesquisado e quando é o trabalhador. Estas quatro dimensões serão fundamentais para entendermos o trabalho do professor de língua materna.

\section{AS DIMENSÕES dO AGIR NO TRABALHO dO PROFESSOR PARA O ENSINO DE LEITURA}

Nesta sessão analisaremos as dimensões do agir que orientam o trabalho docente, especificamente o trabalho interpretado.

$\mathrm{Na}$ dimensão do trabalho interpretado, proposta por Bronckart (1999, 2012), entendemos que o agir se faz presente nesta dimensão, visto que no trabalho interpretado consideramos o que foi planejado individual ou coletivo e o que foi executado no coletivo e o agir é entendido como uma intervenção desempenhada por um agir individual ou coletivo, agir este que pode ser interpretado. Assim, passamos a analisar o trabalho interpretado a partir das noções que compõem o agir, especificamente, as dimensões do agir e as vozes enunciativas que permeiam o discurso e o trabalho docente.

Antes de iniciarmos a nossa leitura dos dados referente ao trabalho interpretado, é importante enfatizar que, segundo Machado e Bronckart (2009, p.29, apud Medrado 2011), "podemos ter acesso ao agir a partir dos discursos e vozes daqueles que executam o trabalho", portanto, analisaremos o agir docente através de leituras das narrativas das sessões de autoconfrontação e da entrevista, uma vez que foi executada pelos professores.

Nos discursos dos colaboradores, sujeitos da pesquisa, identificamos as seguintes dimensões do agir docente: motivacional, intencional e dos recursos ou capacidades, que representam respectivamente: razão que levou o sujeito a agir de determinada maneira; finalidades assumidas pelo coletivo e validadas socialmente, e; instrumentos externos presentes no ambiente social, que podem ser materiais ou tipificações do agir disponíveis ou não para o indivíduo, e as capacidades internas do agente, podendo ser mentais ou comportamentais. Também encontramos o agir de ordem semântica, a exemplo do agir físico, que indica movimentos corporais e gestos e o agir afetivo, que implica um agir emocional. Constatamos também, que a voz do sujeito empírico, isto é, do próprio indivíduo, aparece com maior frequência nos discursos dos docentes, deixando em segundo lugar a voz de personagens, voz precedente de outro agente ou interlocutor, e não encontramos indícios de vozes sociais, que advém dos grupos sociais.

$\mathrm{O}$ agir motivacional de determinante externo que orienta o trabalho docente foi encontrado apenas no discurso de P3, enquanto a dimensão dos motivos do agir, isto é, as razões interiorizadas que levaram os docentes a agir de determinada maneira, foram identificadas nos discursos de P1 e P2 vejamos:

\footnotetext{
${ }^{1}$ Adotaremos a noção de Bronckart $(1999,2012)$ ao enfatizar que o trabalho realizado corresponde ao trabalho real, muito embora Clot (1999) explique que o trabalho realizado não se restringe ao que foi posto em prática, mas considera também o que poderia ter sido feito ou acontecido, assim o trabalho real estaria no plano das reflexões hipotéticas.
} 
(30)

Olha (+) eu tenho a impressão seguinte (+) de que nessa hora aí você está reforçando a importância da leitura, mesmo quando o aluno não faz a leitura, a pessoa que estiver aqui orientando tem/tem que fazer esse reforço, por que (+) porque também é uma forma de você mostrar para o aluno que só quem aprende, só quem domina a aprendizagem, é o autor, é o leitor. (Segunda sessão de autoconfrontação de P1)

(04)

Bem, essa parte aqui, né, é uma parte mais introdutória, que eu sempre tenho essa preocupação, né, de sintonizar o aluno em relação ao que vai acontecer na aula e, é::: geralmente eu trago o material impresso para que eles possam acompanhar, porque muitas vezes o jovem (+) eles ficam muito dispersos, né? Eles conseguem se desconcentrar com muita facilidade, então quando eu faço essa parte introdutória, eu fico caminhando de um lado para o outro, sempre procurando olhar o que o aluno está fazendo em relação ao que eu estou expondo, justamente para que ele não possa perder a concentração. (Primeira sessão de autoconforntação de P2)

(04)

E ontem eu assisti até, eu assisti que tem uma oficina de uma contação de história [...] E o oficineiro dizendo: "Quantas vezes uma palavra da gente estimula ou mata aquela criança, aquela vontade de ler?". Porque ele fala partindo do princípio de que todos nós somos contadores de história. Toda vez que você vai contar uma história é um contador de história e o interlocutor é muito importante nessa contação[...] Então, eu tenho essa mesma visão em relação aos meus alunos na leitura [...] (Segunda sessão de autoconfrontação-P3)

A dimensão do agir motivacional da ordem das razões interiorizadas faz com que o indivíduo atue de modo a dar um significado para suas ações. No relato de P1, vemos a partir do excerto: "que nessa hora aí você está reforçando a importância da leitura, mesmo quando $o$ aluno não faz a leitura, a pessoa que estiver aqui orientando tem/tem que fazer esse reforço" que é no momento da aula, através da explicação do conteúdo realizada pelo professor que o aluno poderá entender a importância da leitura e as expressões em destaque enfatizam essa assertiva. $\mathrm{O}$ uso da conjunção explicativa por que, explica o motivo pelo qual P1 acredita que ministrada uma aula explicando ao aluno a importância da leitura fará com que ele entenda que só quem aprende é o aluno que escreve, é o aluno que lê, assim, o motivo interiorizado que sustenta a atuação de professor é que sua maneira de agir em sala de aula tornará o aluno um sujeito escritor e leitor.

No discurso de P2, ao descrever o seu agir, o docente explica que busca sempre antes de iniciar a aula fazer uma introdução explicando o que acontecerá no decorrer desta para nortear o aluno e para tanto ele traz o material impresso para que os discentes possam acompanhar e não percam a concentração, e assim como $\mathrm{P} 1$, P2 utiliza a conjunção por que para explicar o motivo pelo qual utiliza a estratégia da explicação sobre o conteúdo que será exposto em sala de aula. Nesse sentido, percebemos que o real motivo que leva o professor a fazer uma introdução sobre a aula é para não deixar os alunos dispersos, já que eles perdem muito rápido a concentração.

Ainda no discurso de P2, identificamos no fragmento "quando eu faço essa parte introdutória, eu fico caminhando de um lado para o outro, sempre procurando olhar o que o aluno está fazendo em relação ao que eu estou expondo, justamente para que ele não possa perder a concentração" um agir semântico classificado, neste caso, como agir físico, que é marcado pelos verbos de ação "caminhando", "procurando", flexionados no gerúndio que indicam ação contínua. Assim, a estratégia utilizada pelo docente, de andar pela sala, olhar o 
que os alunos estão fazendo, faz com que o colaborador tenha a noção dos alunos que estão concentrados na aula e os que não estão.

Com relação ao agir físico, $\mathrm{P} 1$ ao refletir sobre o seu agir também deixa explícito que utiliza ações corporais para controlar a turma, conforme atesta o trecho a seguir:

(56)

você tem que estar batendo palma, tem que estar chutando o pé pra ver se você controla a turma. (Primeira sessão de autoconfrontação- P1).

Percebemos que o colaborador utiliza as ações de bater palma, "chutar o pé", que seria bater com o pé no chão, para chamar a atenção dos alunos e fazer com que fiquem quietos.

Os fragmentos analisados de P1 e P2 nos fazem inferir que o agir docente, norteado pela dimensão motivacional internalizada, está pautado em ações voltadas para o benefício do aluno, em que respectivamente, o primeiro busca enfatizar em suas aulas a importância da leitura e o segundo preocupa-se com a concentração dos discentes no processo de aprendizagem.

No que se refere às vozes enunciativas, no discurso de P1 e P2 a voz que se materializa é a voz do sujeito empírico, marcada pelo uso do pronome pessoal "eu", o que demonstra que os docentes assumem a responsabilidade das ações que praticam, tornando a noção de agir centrado apenas no professor, como um agir individualizado.

Diferente da dimensão motivacional de fatores interiorizados, a ordem dos determinantes externos resgata os elementos referentes ao contexto que norteia o trabalho do professor. No relato de P3, observamos que o fato do colaborador ter participado de uma oficina que propunha a importância da leitura, da contação de história em sala de aula, atuou como fator determinante para o agir docente configurando-se como um elemento que compartilhou da mesma noção de leitura, dando credibilidade ao agir de P3, como demonstra o trecho: "Toda vez que você vai contar uma história, é um contador de história e o interlocutor é muito importante nessa contação[...] Então, eu tenho essa mesma visão em relação aos meus alunos na leitura".

Notamos no discurso de P3 duas vozes responsáveis pelo agir, a voz do palestrante, que o docente denomina de oficineiro, configurando uma voz de personagem, e a voz do sujeito empírico, marcada pelo uso repetido do pronome "eu". O colaborador parece trazer essa voz de personagem para mostrar que não apenas ele tem aquela noção referente à leitura, como foi evidenciada anteriormente, já a voz do sujeito empírico enfatiza que foi ele próprio que buscou a oficina como meio de informação, assim, mais uma vez, vemos a concepção de agir pautada na centralização docente.

Quanto à dimensão da intencionalidade, encontramos nos discursos de P1 e $\mathrm{P}^{2}$, dimensões da ordem das intenções, que são formas de agir efetivadas a partir das intenções que levam o indivíduo a agir de determinada forma, geralmente relacionadas ao plano individual, conforme veremos nos excertos a seguir:

(24)

A intenção principal é dotar o aluno de conhecimento (+) a intenção maior é fazer com que ele tenha um conhecimento antecipado do conteúdo que vai ser discutido, pra quê? Pra que quando o aluno/ quando o professor puxa uma discussão, peça pra ele fazer a leitura, ele já tenha pelo menos a metade de domínio... que tenha uma segurança maior [...] Eu considero que você não ter leitura antecipada é::

\footnotetext{
${ }^{2}$ Não encontramos nos discursos de P3 marcas do agir relacionadas à dimensão da intencionalidade.
} 
você ser pego de surpresa, você aí perde (+) acho (+) que 90\% do aprendizado, eu vejo assim. (Segunda sessão de autoconfrontação-P1)

\section{(32)}

[...] Assim (+) a intenção é porque (+) o grande problema da semana de Arte Moderna (+) a semana de Arte Moderna existiu justamente por isso, né, pela influência que Anita Malfatti teve das vanguardas européias [...] Então a grande pergunta que eu queria fazer pra eles era justamente perguntar pra eles se eles eram influenciados por um determinado acontecimento, teórico, ou/ou o que quer que seja, pra mostrar pra eles que nós vivemos em uma sociedade (+) que nós vamos ser influenciados o tempo todo [...] A provocação é porque eu acredito que nós somos influenciados o tempo todo (Primeira sessão de autoconfrontação de P2)

Observamos no segmento supracitado, que a intenção de P1 ao pedir que o aluno faça uma leitura silenciosa do texto é para que os discentes saibam sobre o que vai tratar a aula, seria uma prática de reconhecimento do material a ser discutido e P1 acredita que esse modo de agir auxilia o aluno a ter um domínio e uma segurança maior ao discorrer sobre a temática da aula.

No fragmento relacionado a $\mathrm{P} 2$, a explicação do docente refere-se a uma pergunta que foi direcionada aos alunos, a saber: Vocês são influenciados? Essa indagação foi realizada em meio a uma aula de literatura, cujo tema era a semana de Arte Moderna, segundo o docente a referida indagação foi dirigida aos alunos com o intuito de fazê-los refletir sobre as influências impostas pela sociedade, e tal reflexão parte de uma concepção individualizada do docente.

A partir do trecho "Eu considero que você não ter leitura antecipada é você ser pego de surpresa, você aí perde, acho que 90\% do aprendizado, eu vejo assim", presente no discurso de $\mathrm{P} 1$, constatamos outra dimensão do agir, a dos recursos relacionados à ordem das capacidades, nesta o individuo utiliza recursos mentais e comportamentais (sentimentos, valores, saberes teóricos, conceitos, entre outros) inerentes a uma pessoa em particular. Neste sentido, P1 enfatiza que sob o seu ponto de vista, se o aluno não fizer a leitura prévia, antecipada do texto, ele poderá deixar de aprender o conteúdo, e reforça através da expressão "eu vejo assim" que a concepção que defende está pautada em conceito particular, a voz do sujeito empírico "eu" fica em evidência de modo a enfatizar a individualidade do agir, assim, P1 utiliza dos recursos mentais de ordem da capacidade para explicar a sua forma de agir.

A dimensão da ordem das capacidades também pode ser percebida no discurso de P2, através do excerto: "A provocação é porque eu acredito que nós somos influenciados o tempo todo", no qual identificamos que P2 transmite a ideia de que a discussão só foi possível devido a uma concepção pessoal do professor, o uso do verbo flexionado na primeira pessoa do plural "acredito" e do pronome pessoal "eu", indicando a voz do sujeito empírico, reforça o caráter psicológico e particular da referida ordem do agir.

Diante do exposto, podemos inferir que as dimensões da intencionalidade e das capacidades se complementam, pois os colaboradores ao falarem sobre as intenções que norteiam as suas práticas de atuação, isto é, o agir, apresentam marcas de individualidade, ou seja, a intenção que faz o sujeito agir de determinada forma para alcançar um objetivo está embasada em uma concepção ou crença individualizada pelo próprio sujeito e a voz do sujeito empírico torna-se crucial para enfatizar a noção de particularidade presente nos discursos dos professores.

Com relação ao agir de ordem semântica, percebemos que dos três colaboradores apenas P3, revelou em seu discurso um valor apreciativo de caráter emocional, demonstrando assim, o agir de ordem afetiva, como podemos observar no seguinte trecho: 
(44)

Eu me senti feliz, eu me senti muito feliz porque é isso que eu gosto de fazer ((choro)) Eu gosto de chegar na sala de aula (+) pegar os meus alunos do jeito que estão e dar uma aula e saber que eles gostam do que eu estou dizendo, que eles entendem (+) não tem dinheiro no mundo que pague isso. (Segunda sessão de autoconfrontação- P3)

Observamos no discurso de P3 uma emoção ao falar sobre sua forma de agir em sala de aula, que se sente feliz em poder ministrar uma aula e por saber que está atingindo seu objetivo, que nas entrelinhas do texto, é fazer com que o aluno saia da estagnação e se interesse pela aula, conforme o excerto: "Eu gosto de chegar na sala de aula... pegar os meus alunos do jeito que estão e dar uma aula e saber que eles gostam do que eu estou dizendo". Há no segmento, acima transcrito, verbos denominados de modalizadores apreciativos, que conforme define Bronckart (1999, p.132) são aqueles que avaliam aspectos relativos ao conteúdo temático trazendo um julgamento "subjetivo, apresentando os fatos enunciados como bons, maus, estranho, na visão da instância que avalia", que no caso de P3 a modalização apreciativa é marcada pela forma verbal "gosto".

Em suma, a análise dos dados nos possibilitou verificar que a dimensão do agir que orienta o trabalho do professor, relacionado ao agir realizado, está pautada na dimensão motivacional, uma vez que observamos a referida dimensão nos discursos dos três colaboradores. Assim, pudemos inferir que a dimensão que primeiro orienta o trabalho do professor com a leitura, é a motivacional de ordem dos motivos interiorizados, assim, o motivo que leva o professor a trabalhar com a leitura é individual, por isso a voz do sujeito empírico "eu" aparece com tanta frequência, o que revela o caráter egocêntrico do trabalho docente. Porém, ao olharmos para o trabalho prescritivo e realizado percebemos que há marcas de coletividade, uma vez que o trabalho do professor está ancorado em ações coletivas e para o coletivo.

Em linhas gerais, podemos refletir que o trabalho do professor de língua com a leitura é marcado por conflitos e contradições, pois a intenção em realizar atividades voltadas para a leitura parte de objetivos pessoais, que seria o que "eu" sujeito professor pretendo ensinar, isto quando olhamos para as dimensões do agir, mas em situação de trabalho o pensamento no coletivo aparece, dando lugar ao que "nós" professor e aluno queremos aprender.

Outra reflexão refere-se ao próprio trabalho com a leitura, que parece estar sempre vinculada à atividade de escrita ou é utilizada para reconhecimento do conteúdo a ser estudado, o que nos faz inferir que os professores não trabalham a leitura de modo significativo, contribuindo para a formação de leitores críticos e proficientes. Conforme evidencia Antunes (2003), o professor de língua materna deveria promover para seus alunos aulas que tomem por objetivo o ensino de leitura, para tanto poderia levar para sala de aula uma leitura de textos autênticos, interativa, para que possa juntamente com os alunos construir o sentido do texto, uma leitura do texto como um todo, e não de fragmentos presentes no livro didático e o principal, uma leitura diversificada, tal como os alunos fazem fora de sala de aula.

\section{CONSIDERAÇÕES FINAIS}

Por meio da análise realizada acerca do agir docente em aulas de leitura podemos perceber que as três dimensões do agir (motivacional, intencional e de recursos) se fazem presentes em seus discursos, sendo que o agir motivacional da ordem da internalização foi 
encontrado nos discursos de $\mathrm{P} 1$ e P2, revelando assim que estes docentes trabalham a leitura a partir de motivos mentais particulares, enquanto P3, que enfatizou o agir motivacional da ordem dos determinantes externos, utiliza do discurso do meio social para validar suas concepções de trabalho.

Assim como Machado e Bronckart (2009) acreditamos que o trabalho do professor é uma prática complexa que envolve seu ser integral em diferentes dimensões (físicas, afetivas, linguageiras, entre outras), cujo objetivo é propiciar meios que favoreçam a aprendizagem e o desenvolvimento do aluno. E para execução do trabalho docente é necessário atividades pautadas em prescrições que serão materializadas a partir da interação constante com os demais indivíduos envolvidos, por isso o trabalho docente não é isolado, ele envolve uma rede de interações que nem sempre são harmoniosas.

\section{REFERÊNCIAS}

ANTUNES, Irandé. Aula de Português: encontro e interação. São Paulo: Parábola Editorial, 2003.

BRONCKART, J.P .; MACHADO, A. R. Por que e como analisar o trabalho do professor. In: BRONCKART, J.P.. Atividade de Linguagem, Discurso e Desenvolvimento Humano. São Paulo: Mercado de Letras, 2009, p. 203-229.

BRONCKART, J. P. Atividade de linguagem, textos e discursos: por um Interacionismo Sociodiscursivo. São Paulo: EDUC, 2012 [1999].

O agir nos discursos: das concepções teóricas às concepções dos trabalhadores. Campinas: Mercado de Letras, 2008.

CLOT, Y. A função psicológica do trabalho. 2 ed. Tradução: Adail Sobral. Rio de Janeiro, Petrópolis: Vozes, 2007/[1999].

GONSALVES, Elisa Pereira. Escolhendo o percurso metodológico. In: Conversas sobre iniciação a pesquisa científica. Campinas, SP. Editora Alínea, 2007, p. 63-73.

PEREIRA, Regina Celi Mendes. A construção social e psicológica de texto escrito. In: PEREIRA, Regina Celi Mendes; ROCA, Maria Del PILAR. (Orgs.). Linguística Aplicada: um caminho com diferentes acessos. São Paulo: Contexto, 2009, p. 113-142.

MEDRADO, Betânia Passos. Compreensão da docência como trabalho: reflexões e pesquisas na/da Linguística Aplicada. In: MEDRADO, B. P.; PÉREZ, M. (Orgs.). Leituras do agir docente: a atividade educacional à luz da perspectiva Interacionista Sociodiscursiva. Campinas: Pontes, 2011, p. 21-36.

RODRIGUES, Maria Anunciada Nery. As (re)configurações construídas sobre o agir do professor em relatórios de estágio. In: MEDRADO, B. P.; PÉREZ, M. (Orgs.). Leituras do agir docente: a atividade educacional à luz da perspectiva Interacionista Sociodiscursiva. Campinas: Pontes, 2011, p129-156. 
Recebido em: 15 de fevereiro de 2016.

Aceito em: 31 de julho de 2016. 